\title{
Molecular study of HCV detection, genotypes and their routes of transmission in North West Frontier Province, Pakistan
}

\author{
Sher Zaman Safi* ${ }^{1 *}$ Yasir Waheed ${ }^{1}$, Joharia Sadat ${ }^{1}$, Solat-Ul-Islam ${ }^{2}$, Sadia Salahuddin ${ }^{1}$, Umar Saeed ${ }^{1}$, Muhammad Ashraf \\ ${ }^{1}$ Atta-ur-Rahman School of Applied Biosciences (ASAB), National University of Science and Technology (NUST), Islamabad, Pakistan \\ ${ }^{2}$ Lady Reading Hospital (L.R.H) Peshawar, Pakistan
}

\section{ARTICLE INFO}

\section{Article history:}

Received 23 September 2011

Received in revised form 27 October 2011

Accepted 28 December 2011

Available online 28 July 2012

\section{Keywords:}

$\mathrm{HCV}$

Genotypes

Subtype 3a

Risk factors

NWFP

Transmission

Molecular study

PCR

\section{ABSTRACT}

Objective: To determine hepatitis $\mathrm{C}$ virus (HCV) genotypes and explore the associated risk factors in chronic HCV patients. Methods: A total of 116 patients with chronic hepatitis C were subjected to polymerase chain reaction (PCR) based detection out of which 112 chronic HCV patients [53 male $(47.32 \%)$, 59 female $(52.68 \%)$; mean age $(43.76 \pm 16.40)$ years; mean BMI $(23.8 \pm 3.9)$ $\mathrm{kg}$ ] were enrolled in this study. The frequency of $6 \mathrm{HCV}$ genotypes and associated risk factors were evaluated from five districts of North West Frontier Province (NWFP). Results: Genotype 3 was the most prevalent in 73 samples $(65.17 \%)$ followed by genotype 1 in $24(21.42 \%)$ and genotype 2 in $13(11.60 \%)$ samples. Genotype 3 had significantly high prevalence $(P=0.0002)$. The results showed that $48(42.85 \%)$ samples were infected with HCV 3a; 25 (22.32\%) with 3b; $14(12.50 \%)$ with 1a; $10(8.92 \%)$ with $1 \mathrm{~b} ; 11(9.82 \%)$ with $2 \mathrm{a} ; 2(1.78 \%)$ with $2 \mathrm{~b}$; and 2 were untypable. The distribution of HCV genotypes in Mardan, Charsadda, Peshawar, Sawabi and Nowshehra districts was different. Use of unsterile equipment for medication, barbers and previous history of hospitalization were the main risk factors for HCV transmission. Conclusions: Genotype $3 \mathrm{a}$ and $3 \mathrm{~b}, 1 \mathrm{a}, 1 \mathrm{~b}$ and $2 \mathrm{a}$ are the common genotypes in NWFP. Genotype 4, 5, and 6 can not be found in a single sample. The level of awareness about various modes of transmission of HCV among the population is found to be very low.

\section{Introduction}

Hepatitis C virus (HCV) was acknowledged in 1989 by Choo et al[1] and classified into the family Flaviviridae[2]. It is a single stranded enveloped RNA virus of $9.6 \mathrm{~kb}$ genome with three structural and six nonstructural proteins. The structural proteins are core, E1 and E2 and these have a substantial heterogeneity due to the lack of efficient proofreading ability during the replication process[3,4]. This variability has led to viral classification into at least 6 genotypes and over 100 subtypes on the basis of molecular relatedness[5-7]. Experiments conducted on Huh7 cell lines have shown that HCV virions present a natural integrity and infectivity, which opens up new opportunities to improve the therapeutic strategies for the treatment of HCV[8].

\footnotetext{
*Corresponding author: Mr. Sher Zaman Safi, PhD Scholar, NUST Center of Virology and Immunology, National University of Sciences \& Technology, H-12 Islamabad Pakistan.

Tel: $+92-313-5393030$

Fax: +92-51-9271593

E-mail: safi.nust@yahoo.com

Foundation Project: This work was financially supported by Higher Education Commission (HEC) of Pakistan.
}

It is imperative to determine HCV genotypes and subtypes to cope with the clinical management, prognosis and assessment of patients before consideration of interferon therapy. HCV is classified into 11 major genotypes and more than 100 subtypes. Genotypes 1-3 have worldwide distribution. The rest of the genotypes show definite geographic site predilections. Types $1 \mathrm{a}$ and $1 \mathrm{~b}$ are the most prevalent in the world especially in United States and Europe[9,10]. In Japan, 73\% of infections are caused by subtype $1 \mathrm{~b}[11]$. HCV subtypes $2 \mathrm{a}$ and $2 \mathrm{~b}$ are found commonly in North America and Europe. In Northern Italy, subtype $2 c$ is the dominant one[12]. In South-East Asia, genotype 3 is most common. Type 4 is found in Middle East, Egypt and central Africa. The South African population is mostly infected with genotype 5[13]. Genotype 6 is found in the population of Hong Kong[14]. The Vietnamese population harbors geographically isolated genotypes 7, 8 and 9 while genotypes 10 and 11 are acknowledged in Indonesian HCV infected patients[12].

People not habitually adopting proper hygiene measures and no implementation of international standards in procedures like blood transfusion, reuse of injection needles, injecting drug users, tattooing, getting a shave from 
barbers, use of unsterilized needles for ear and nose piercing and use of unsterilized surgical instruments are the key factors of HCV transmission in Pakistan[12,15]. Worldwide, there are about 170 million people being infected with HCV, and 3-4 million individuals are diagnosed as new cases every year. In Pakistan, 10 million people are presumed to have HCV, with 5\% prevalence in the general population[15]. This number is going to increase with the passage of time due to the lack of awareness, resources and health care safety measures.

Pakistan shares its borders with four neighboring countries, Afghanistan, China, India and Iran. North West Frontier Province of Pakistan (NWFP) lies beside Afghanistan, with a shared border of $2430 \mathrm{~km}[16]$. Very little is known about the epidemiology and associated risk factors of viral hepatitis like HCV and hepatitis B virus (HBV) in this province. Data regarding HCV genotypes are still lacking in this region which has a population of 19.63 million[17]. Most of the work in this direction has been done in other provinces of Pakistan like Punjab and Sindh. Thus tremendous efforts are needed to increase the awareness about the genotypes of $\mathrm{HCV}$ and various risk factors involved in their transmission in this province. Therefore, the present study was aimed to determine the genotypes of HCV and explore the associated risk factors in chronic $\mathrm{HCV}$ patients.

\section{Materials and methods}

\subsection{Patients and samples}

The present study was carried out from June 2009 to February 2010, at NUST Centre of Virology and Immunology (NCVI), National University of Science and Technology, in collaboration with Government Lady Reading Hospital (LRH), Peshawar, Pakistan (a major hospital in this Province). The study was approved by the Ethical Committee of Nust Centre of Virology and Immunology, NUST.

A total of 116 consecutive patients with chronic hepatitis C who came from 5 different districts of NWFP, including Mardan, Charsadda, Peshawar, Nowshehra and Sawabi were included in the study. Whole blood samples were collected in BD vacutainer tubes. Seventy blood samples from chronic HCV patients (mostly with cirrhosis and liver carcinoma) were collected from LRH in Peshawar while 46 were collected from different diagnostic labs and health care centers in Charsadda, Nowshehra, Mardan and Sawabi. The patients in LRH were hospitalized from different districts due to severe HCV infection. All the samples were seropositive for anti-HCV by second-generation enzyme

Table 1

Primers used for genotyping.

\begin{tabular}{|c|c|c|c|}
\hline Name & Mix 1 primers & Name & Mix 2 primers \\
\hline S7 & AGACCGTGCACCATGAGCAC & $\mathrm{S} 7$ & AGACCGTGCACCATGAGCAC \\
\hline $\mathrm{S} 2 \mathrm{a}$ & AACACTAACCGTCGCCCACAA & G1a & GGATAGGCTGACGTCTACCT \\
\hline G1b & CCTGCCCTCGGGTTGGCTA(AG) & G3a & GCCCAGGACCGGCCTTCGCT \\
\hline G2a & CACGTGGCTGGGATCGCTCC & G4 & CCCGGGAACTTAACGTCCAT \\
\hline $\mathrm{G} 2 \mathrm{~b}$ & GGCCCCAATTAGGACGAGAC & G5a & GAACCTCGGGGGGAGAGCAA \\
\hline G3b & CGCTCGGAAGTCTTACGTAC & G6a & GGTCATTGGGGCCCCAATGT \\
\hline
\end{tabular}

linked immunosorbent assay (ELISA). Patients who had any serological evidence of infection with other viruses like HIV, HBV and HDV were excluded from this study.

\subsection{Molecular screening of the study subjects}

Serum of 116 chronic HCV patients was collected from whole blood and then it was subjected to RNA extraction, using Qiagen (Germany) RNA isolation kit according to the protocols of the manufacturer. Viral RNA $(10 \mu \mathrm{L})$ was used to reversely transcribe the $5^{\prime}$ UTR by using Moloney murine Leukemia Virus Reverse Transcriptase (M-mLV RTase, Fermentas) in a reaction volume of $20 \mu \mathrm{L}$ for $60 \mathrm{~min}$ at $37^{\circ} \mathrm{C}$.

The amplified cDNA of HCV 5' UTR was used for qualitative analysis. The 1st round PCR reaction was made by using outer sense and antisense primers and then a 2nd round nested PCR was performed using inner primers. The 1st round PCR product $(2 \mu \mathrm{L})$ was used as a template for the 2nd round nested PCR. Both the 1st and 2nd round PCR were amplified with Taq DNA polymerase (Fermentas) for 35 cycles. Amplified DNA fragments of the 2nd round were run on 1.5\% agarose gel electrophoresis and visualized by using a gel documentation system (Wealtec) (Figure 1). Out of 116 samples, 4 proved to be HCV negative while 112 were HCV positive after qualitative analysis by PCR.

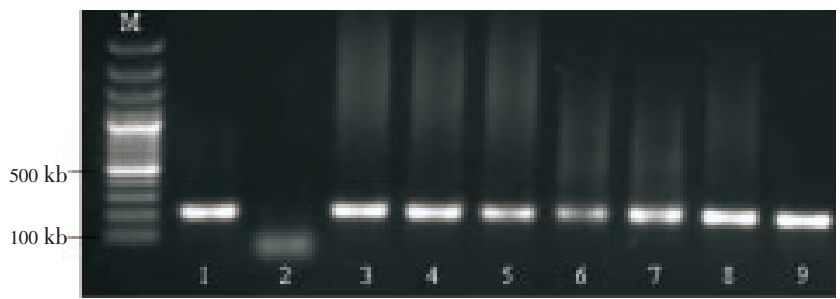

Figure 1. Electrophoresis pattern of some samples, performed for qualitative analysis.

Lanes 1, 3, 4, 5, 6, 7, 8 \& 9 contain bands which are HCV positive while lane 2 is a negative control.

\subsection{Genotyping of HCV positive patients}

All HCV positive patients were then screened for genotyping. Screening was done for 6 different genotypes by using the method of Ohno et al[18] with slight amendment. Viral RNA $(10 \mu \mathrm{L})$ was used to synthesize cDNA through reverse transcription using $200 \mathrm{U}$ of $\mathrm{M}-\mathrm{mLV}$ RT at $37{ }^{\circ} \mathrm{C}$ for $60 \mathrm{~min}$. The first round PCR was carried out using $10 \mu \mathrm{L}$ of the synthesized cDNA using 5'-GGGAGGTCTCGTAGACGGTGC ACCATG $-3^{\prime}$ as forward primer and 5'-GAGACGGGTATAGT ACCCCATGAGAGTCGGC-3' as reverse primer. The product from the 1st round $(5 \mu \mathrm{L})$ was then taken to perform a 2 nd round PCR in the form of Mix 1 and Mix 2. Mix 1 contained 
primers for genotype $2 \mathrm{a}, 2 \mathrm{~b}, 3 \mathrm{~b}$ and $1 \mathrm{~b}$ while genotype 1a, $3 \mathrm{a}$, 4, 5a and 6a were in Mix 2 (Table 1). All PCR amplification reactions were performed by using Taq DNA Polymerase (Fermentas). The 2 nd round PCR products $(5 \mu \mathrm{L})$ were electrophoresed on 1.5\% agarose gel with 100 bp DNA marker and visualized in gel doc system (Wealtec) (Figure 2). HCV genotype confirmation was done on the basis of specific PCR bands.
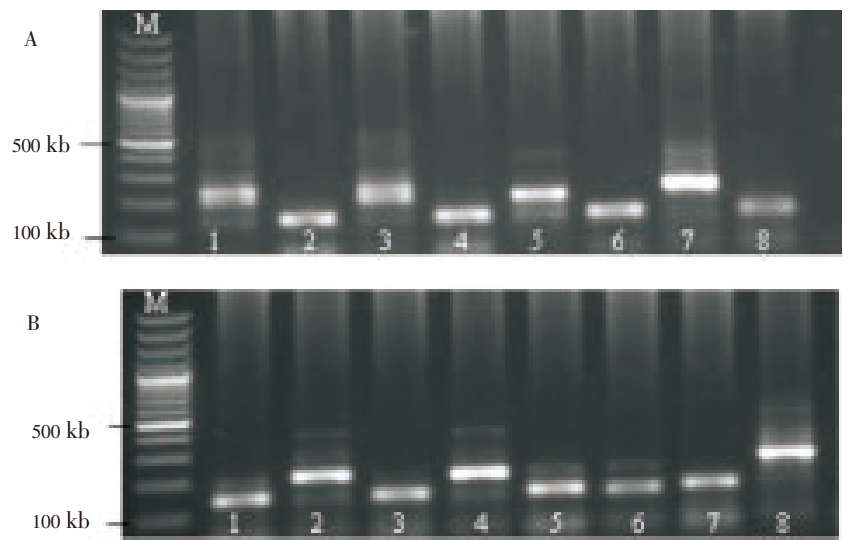

Figure 2. Genotyping of HCV positive patients using agarose gel electrophoresis.

A: Lanes 1, 3 \& 5 amplified bands represent genotype 3a, lanes 2, 4, 6 $\& 8$ represent genotype $2 \mathrm{a}$ and lane 7 shows genotype $1 \mathrm{~b}$; B: Lanes 3,5 , $6 \& 7$ represent genotype 3 b, lanes $2 \& 4$ represent genotype 3a, lane 1 represents genotype $2 \mathrm{a}$ while lane 8 shows genotype $2 \mathrm{~b}$.

\subsection{Data collection}

No provincial data collection system exists for the evaluation of common risk factors associated with HCV transmission. For this reason HCV frequently enters this population, with a variety of modes of transmission. Data were collected by conducting interviews with each of the study subjects and using a questionnaire.

\subsection{Statistical analysis}

In the statistical analysis, clinical variables were presented as mean \pm SD, $P$ value and $C I(95 \%)$ were calculated and compared by using independent $t$-test and $C h i$ square test. In the case of $P$ values, a significance of 5\% was assumed. Data analysis was accomplished using the computer software, SPSS for windows. $P$ value for the risk factors was calculated using CreoStat HB (Version 1.0.4).

\section{Results}

Table 2

Distribution of HCV genotypes in five districts of NWFP $[n(\%)]$.

\begin{tabular}{ccrccccccc}
\hline Districts & Total isolates & \multicolumn{4}{c}{ Distribution of HCV genotypes in NWFP } & \multicolumn{2}{c}{ Analysis } \\
\cline { 3 - 8 } & & $3 \mathrm{a}(n=48)$ & $3 \mathrm{~b}(n=25)$ & $1 \mathrm{a}(n=14)$ & $1 \mathrm{~b}(n=10)$ & $2 \mathrm{a}(n=11)$ & 2b/Untypable* & \multicolumn{1}{c}{$C(95 \%)$} & $P$ value \\
\hline Peshawar & 26 & $11(42.3)$ & $7(26.9)$ & $2(7.7)$ & $2(7.7)$ & $3(11.5)$ & $1(3.8)$ & $0.98-32.30$ & 0.041 \\
Nowshehra & 19 & $9(47.4)$ & $4(21.0)$ & $3(15.8)$ & $1(5.3)$ & $2(10.5)$ & $0(0.0)$ & $-0.95-34.30$ & 0.060 \\
Charsadda & 27 & $10(37.0)$ & $6(22.2)$ & $3(11.1)$ & $3(11.1)$ & $3(11.1)$ & $2 *(7.4)$ & $4.90-28.40$ & 0.015 \\
Mardan & 17 & $8(47.0)$ & $3(17.6)$ & $2(11.8)$ & $2(11.8)$ & $2(11.8)$ & $0(0.0)$ & $-0.58-33.40$ & 0.050 \\
Sawabi & 23 & $10(43.5)$ & $5(21.7)$ & $4(17.4)$ & $2(8.7)$ & $1(4.3)$ & $1(4.3)$ & $0.97-32.30$ & 0.040 \\
\hline
\end{tabular}

\subsection{Genotypes}

Among the 116 patients with chronic hepatitis C (by ELISA and PCR) screened for qualitative analysis by PCR, 112 patients [53 male $(47.32 \%), 59$ female $(52.68 \%)$; mean age $(43.76 \pm 16.40)$ years; mean BMI $(23.8 \pm 3.9) \mathrm{kg}]$ were $\mathrm{HCV}$ positive. The frequency distribution of HCV genotypes and subtypes in 112 patients was determined. In the 112 PCR positive samples, genotype 3 was the most prevalent genotype $(73,65.17 \%)$ followed by genotype $1(24,21.42 \%)$ and genotype $2(13,11.60 \%)$. Genotype 3 had significantly high prevalence $(P=0.0002)$ in the Pakistani population. Among the subtypes, $48(42.85 \%)$ samples were HCV $3 \mathrm{a}$, and $3 \mathrm{~b}$ was found in $25(22.32 \%)$ patients, $14(12.50 \%)$ were genotype 1a, $10(8.92 \%)$ genotype $1 \mathrm{~b}, 11(9.82 \%)$ genotype $2 \mathrm{a}, 2(1.78 \%)$ genotype $2 \mathrm{~b}$ while $2(1.78 \%)$ samples revealed no result, and were considered to be untypable by the genotyping system of Ohno et al. Details of HCV prevalence in different districts of NWFP were shown in Table 2 and Figure 3. In the 8 different areas of the province, HCV genotypes $3 \mathrm{a}, 3 \mathrm{~b}$, 2a, 1a, 1b were the most prevalent in Nowshehra (47.4\%), Peshawar (26.9\%), Mardan (11.8\%), Sawabi (17.4\%) and Mardan (11.8\%), respectively, and the least prevalent in Charsadda (37.0\%), Mardan (17.6\%), Sawabi (4.3\%), Peshawar (7.7\%) and Nowshehra $(5.3 \%)$. HCV genotypes in 4 districts showed a significantly different distribution, Peshawar $(P=0.041)$, Charsadda $(P=0.015)$, Mardan $(P=0.050)$ and Sawabi $(P=0.040)$ and the difference was nonsignificant in Nowshehra district $(P=0.060)$. Genotype $2 \mathrm{~b}$ was found in samples from Peshawar and Sawabi while both of the untypable samples were from HCV patients of Charsadda district.

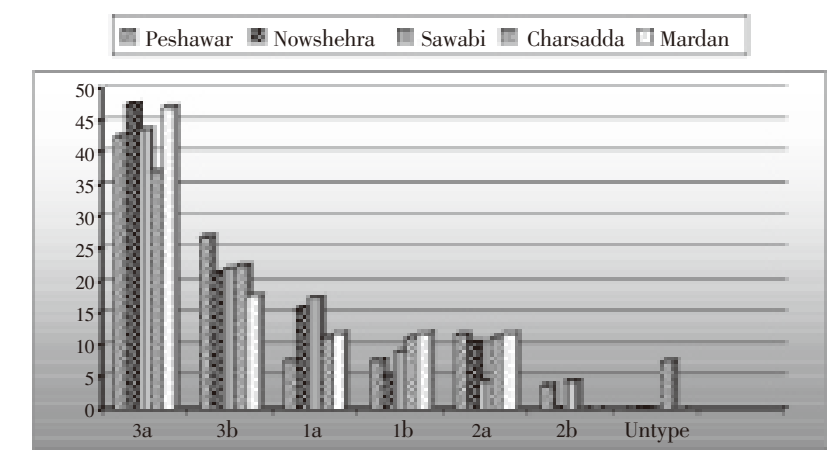

Figure 3. Graphical representation of HCV genotypes in five different districts of NWFP.

\subsection{Risk factors}


Our data suggested that a variety of risk factors were responsible for the transmission of $\mathrm{HCV}$ in NWFP $(95 \%$ CI: -1.1-14.1). All the HCV exposed patients were divided into 12 categories. There were $14(12.5 \%)$ cases $(P=0.037)$ who had contracted the virus due to the re-use of syringes from untrained rural health care workers and injection drug users; 4 (3.57\%) cases $(P=0.613)$ were because of minor cuts and injuries being exposed to contaminated water; 5 $(4.46 \%)$ patients were infected due to the use of different contaminated equipment, including that for dental invasive procedures and root canal treatments $(P=0.872)$. There were $7(6.25 \%, P=0.655)$ cases thought to be associated with a medical history of several surgeries and long-term hospitalization, while 8 (7.14\%) patients claimed multiple transfusions $(P=0.476)$. Haemodialysis and non-sexual household contacts accounted for $6(5.35 \%)$ cases each $(P=0.877$ for each). Factors for HCV transmission in $7(6.25 \%$, $P=0.655)$ patients were shaving or circumcision from barber shops, tattooing and sharing razors; $3(2.67 \%, P=0.300)$ female cases were found who contracted the infection during handling child delivery cases at home (non professional); $5(4.46 \%)$ patients were infected while working in different hospitals and health care centers $(P=0.872)$. Only $2(1.78 \%$, $P=0.144)$ cases were observed with infection from using and sharing contaminated tooth brushes and nail cutters. A single HCV positive patient $(0.89 \%)$ claimed to have contracted the infection from her husband, indicating a sexual mode of transmission (significantly low, $P=0.050$ ). We did not find any cases of transmission of HCV infection from infected mother to baby. In $44(39.28 \%)$ patients no route of transmission could be established.

\section{Discussion}

In Pakistan, very little research work has been carried out on the epidemiology, genotypes and likely risk factors associated with the transmission of HCV[19]. HCV is a blood borne disease and spreads through intravenous drug users, by sharing of tooth brushes, contaminated needles, sexual relations, from mother to child and by getting a shave from community barbers, which is a very common practice in Pakistan[20]. According to the United Nations ranking, Pakistan stands at the 134th position amongst 170 developing countries due to a lack of basic health facilities and educational standards providence[21]. People in NWFP have the least of the above mentioned facilities, awareness and educational standards to combat the infection of HCV by self care and appropriate interferon therapies. This study was carried out in different regions of NWFP to investigate the prevalence of HCV genotypes and their possible infection causes in the HCV infected population.

$\mathrm{HCV}$ is one of the major causes of chronic hepatitis, and patients with persistent HCV infection have a high incidence of hepatocellular carcinoma (HCC)[17]. High genetic heterogeneity has been noted for HCV, with a nucleotide substitution rate of $1.44 \times 10^{-3}-1.92 \times 10^{-3}$ per site per year[22]. These mutations result in diversification and evolution of different HCV genotypes. It is evident that patients infected by different genotypes show a difference in severity of liver diseases and a different response to interferon therapy[18]. Knowledge of HCV genotypes provides important information about epidemiology and therapy. Over the past decade, major improvements have been made in the treatment and handling of chronic hepatitis C, especially with the introduction of combined therapy of using both interferon and ribavirin. The most optimal dose and proper duration of treatment is still a matter of debate. However, HCV genotype influences the severity of disease as well as the response to interferon therapy[23]. Generally, patients infected with HCV genotypes 2 or 3 more readily achieve a sustained viral response (SVR) than those infected with HCV genotype 1. An SVR is achieved in $61 \%$ of HCV patients getting interferon therapy[24]. Several studies have shown an association between HCV genotype and both the responsiveness to interferon treatment and the extent of clinical progression of chronic HCV infection[25]. Thus it is imperative for health care providers to know about genotype before giving therapy to the patient. A convenient and reliable HCV genotyping system is obligatory for studying genotypes in HCV patients for proper treatment.

Our study indicates $3 \mathrm{a}$ is the most common genotype in the sampled population. These results are consistent with the studies reported from other provinces of Pakistan and other countries in the area i.e. India, Nepal and Bangladesh[26]. However, there is a minor difference especially with respect to $3 \mathrm{a}$ and $3 \mathrm{~b}$ prevalence than other studies. Our study shows a greater frequency of $3 \mathrm{~b}$ and a lower distribution of $3 \mathrm{a}$ as compared to the previous studies. However, this difference is non significant, and can be regarded as consistent with all the studies conducted previously. According to the present study, genotype $3 \mathrm{a}$ is the most frequent subtype in NWFP population $(P=0.0002)$, which may render them prone to steatosis, followed by other liver complications with greater frequency than the rest of the world. Intravenous drug users and re-use of syringes make a significant contribution in the spread of HCV $(P=0.037)$. Other risk factors are not significantly involved while sexual transmission is significantly low $(P=0.032)$.

Two undetectable (untypable) samples were further tested by a different genotyping system reported by Idrees[27] but no band was observed in either sample. The presence of untypable samples in previous reports from Pakistan and in our study indicates neither the genotyping methods of Ohno et al nor Idrees are able to detect these genotypes or some novel genotypes are present in Pakistan. So the cloning and sequencing of these samples would be very useful to solve this mystery and to help health care workers to prescribe appropriate therapy for patients with untypable genotypes. Our next goal is to determine the genetic sequence of the untypable HCV region, so the reasons for untypable samples can be established. 
Genotypes $3 \mathrm{a}$ and $3 \mathrm{~b}$ are the common genotypes in NWFP with slight differences from other provinces of Pakistan. In NWFP, 3a is less frequent while $3 b$ is more frequent than other provinces of Pakistan. Genotypes 1a, 1b, 2a and $2 \mathrm{~b}$ are also present in the population, while genotypes 4,5 , and 6 were not found in any sample. There is considerable variation in the prevalence of different genotypes and subtypes in 5 areas of NWFP. There is little awareness about the various modes of transmission of HCV among the population. Re-use of syringes and intravenous drug users contribute significantly to $\mathrm{HCV}$ transmission $(P=0.037)$. A predominant number of them are considering interferon treatment as a vaccination strategy for hepatitis B and C.

\section{Conflict of interest statement}

We declare that we have no conflict of interest.

\section{Acknowledgements}

This work was supported by Higher Education Commission (HEC) of Pakistan and US-Pakistan grant.

\section{References}

[1] Choo QL, Kuo G, Weiner AJ, Overby LR, Bradley DW, Houghton M. Isolation of a cDNA clone derived from a bloodborne non-A, non-B hepatitis genome. Science 1989; 244: 359-362.

[2] Safi SZ, Badshah Y, Waheed Y, Fatima K, Tahir S, Shinwari A, et al. Distribution of hepatitis C virus genotypes, hepatic steatosis and their correlation with clinical and virological factors in Pakistan. Asian Biomed 2010; 4(2): 253-262.

[3] Jamall IS, Yousaf S, Azhar M, Jamall S. Is pegylated interferon superior to interferon with ribavarin, in chronic hepatitis C genotypes 2/3? World J Gastroenterol 2008; 14: 6627-6631.

[4] Argentini C, Genovese D, Dettori S, Rapicetta M. HCV genetic variability: from quasispecies evolution to genotype classification. Future Microbiol 2009; 4: 359-373.

[5] Akhund AA, Shaikh KR, Naqvi SQH, Kamal M. HCV genotypes in correlation to histopathological grading and staging in interior Sindh. Gomal J Med Sci 2008; 6: 93-97.

[6] Khan S, Attaullah S, Ali I, Ayaz S, Naseemullah, Khan SN, et al. Rising burden of hepatitis $\mathrm{C}$ virus in hemodialysis patients. Virol J 2011; 8: 2-5.

[7] Chevaliez S, Bouvier-Alias M, Brillet R, Pawlotsky JM. Hepatitis C virus (HCV) genotype 1 subtype identification in new HCV drug development and future clinical practice. PLoS One 2009; 4(12): e8209.

[8] Guo J, Yan R, Xu G, Li W, Zheng C. Construction of the Vero cell culture system that can produce infectious HCV particles. Mol Biol Rep 2007; 36: 111-120.

[9] Foote BC, Spooner LM, Belliveau PP. Boceprevir: a protease inhibitor for the treatment of chronic hepatitis C. Ann Pharmacother 2011; 45(9): 1085-1093.

[10] Ashfaq UA, Khan SN, Nawaz Z, Riazuddin S. In-vitro model systems to study hepatitis C virus. Genet Vaccines Ther 2011; 9: 7.

[11] Gheith OAA. Dilemma of HCV infection in renal transplant recipients. Int J Nephrol 2011; 2011: 1-7.

[12] Ali S, Ali I, Azam S, Ahmad B. Frequency distribution of HCV genotypes among chronic hepatitis C patients of Khyber Pakhtunkhwa. Virol J 2011; 8: 193.

[13] Kamal SM, Nasse AI. Hepatitis C genotype 4: what we know and what we don't yet know. Hepatology 2008; 47: 1371-1383.

[14] Chao DT, Abe K, Nguyen MH. Systematic review: epidemiology of hepatitis C genotype 6 and its management. Aliment Pharmacol Ther 2011; 34: 286-296.

[15] Lavanchy D. Evolving epidemiology of hepatitis C virus. Clin Microbiol Infect 2011; 17: 107-115.

[16] Government of Pakistan, Ministry of Commerce. [Online] Available from: http://www.commerce.gov.pk/?page_id=77 [Accessed on 20 July, 2011].

[17] Janjua NZ, Nizamy MA. Knowledge and practices of barbers about hepatitis B and C transmission in Rawalpindi and Islamabad. J Pak Med Assoc 2004; 54: 116.

[18] Ohno O, Mezokami M, Wu R, Saleh MG, Ohba K, Orito E, et al. New hepatitis $\mathrm{C}$ virus (HCV) genotyping system that allows for identification of HCV genotypes 1a, 1b, 2a, 2b, 3a, 3b, 4, 5a, and 6a. J Clin Microbiol 1997; 35: 201-202.

[19] Waheed Y, Shafi T, Safi SZ, Qadri I. Hepatitis C virus in Pakistan: a review of prevalence and risk factors. World $J$ Gastroenterol 2009; 15(45): 5647-5653.

[20] Waheed Y, Saeed U, Safi SZ, Chaudhry WN, Qadri I. Awareness and risk factors associated with barbers in transmission of hepatitis B and C from Pakistani population: barber's role in viral transmission. Asian Biomed 2010; 4: 435-442.

[21] United Nations Development Program. Human development report 1996. New York: Oxford University Press; 1996.

[22] Ogata N, Alter HJ, Miller RH, Purcel RH. Nucleotide sequence and mutation rate of the $\mathrm{H}$ strain of hepatitis $\mathrm{C}$ virus. Proc Natl Acad Sci USA 1991; 88: 3391-3396.

[23] Jang JY, Chung RT. Chronic hepatitis C. Gut Liver 2011; 5(2): $117-132$.

[24] Bjøro K, Bell H, Myrvang B, Skaug K, Raknerud N, Sandvei $\mathrm{P}$, et al. Effect of interferon-alpha induction therapy on genotype $2 \mathrm{~b} / 3 \mathrm{a}$ and low viral load hepatitis $\mathrm{C}$ virus infection. A randomized multicentre study. Scand J Gastroenterol 2002; 37(3): 344-349.

[25] Hofmann WP, Zeuzem S. A new standard of care for the treatment of chronic HCV infection. Nat Rev Gastroenterol Hepatol 2011; 8: 257-264.

[26] Afridi S, Naeem M, Hussain A, Kakar N, Babar ME, Ahmad J. Prevalence of hepatitis C virus (HCV) genotypes in Balochistan. Mol Biol Rep 2009; 36(6): 1511-1514.

[27] Idrees M. Development of an improved HCV genotyping assay for the detection of common genotypes and subtypes in Pakistan. J Virol Methods 2008; 150: 50-56. 